\title{
Cusp Restricted Motion Indicator
}

National Cancer Institute

\section{Source}

National Cancer Institute. Cusp Restricted Motion Indicator. NCI Thesaurus. Code C127556.

An indication as to whether there is restricted motion of a cardiac valve cusp. 